\title{
EDUCAÇÃO POPULAR NA PARAÍBA: MEMÓRIA E HISTÓRIA DO SEDUP
}

\author{
POPULAR EDUCATION IN PARAÍBA: MEMORY AND HISTORY OF SEDUP
}

EDUCACIÓN POPULAR EN PARAÍBA: MEMORIA E HISTORIA DEL SEDUP

MOREIRA, Orlandil de Lima ${ }^{1}$

ZITKOSKI, Jaime José2

\section{RESUMO}

O artigo apresenta como problemática a contribuição do Serviço de Educação Popular (SEDUP) para o movimento de Educação popular na Paraíba, evidenciado pela sua história e pela sua memória em dois períodos, o de resistência ao autoritarismo militar e o da transição democrática, que correspondem às décadas de 1980 e de 1990. A pesquisa tem um caráter qualitativo, com a investigação realizada por meio de fontes documentais. Em sua trajetória, o SEDUP desenvolveu uma ação educativa popular, tendo como sujeitos as classes subalternas com toda a sua diversidade, e pertencentes a territórios rurais e urbanos, partindo de uma perspectiva de educação emancipatória.

Palavras-chave: Educação Popular. História. Memória. SEDUP

\section{ABSTRACT}

The paper presents the adversities and contributions of the Popular Education Service (SEDUP) to the Popular Education movement in Paraiba, evidenced by its history and memory in two periods, that of resistance to military authoritarianism and the democratic transition, which corresponds to the decades 1980 and 1990 . The research has a qualitative type, with the investigation carried out through documentary sources. In its trajectory, SEDUP developed a popular educational action, with subaltern classes with all their diversity, and belonging to rural and urban territories, starting from an emancipatory education perspective.

Keywords: Popular Education. History. Memory. SEDUP.

\section{RESUMEN}

El artículo presenta como problemática la contribución del Servicio de Educación Popular (SEDUP) al movimiento de Educación Popular en Paraíba, evidenciada por su historia y memoria en dos períodos, el de la resistencia al autoritarismo militar y la transición democrática, que corresponde a las décadas 1980 y 1990. La investigación tiene un carácter cualitativo, siendo la investigación realizada a través de fuentes documentales. En su trayectoria, la SEDUP desarrolló una acción educativa popular, conteniendo clases subalternas con toda su diversidad, y pertenecientes a territorios rurales y urbanos, partiendo de una perspectiva de educación emancipadora.

Palabras clave: Educación Popular. Historia. Memoria. SEDUP.

\footnotetext{
${ }^{1}$ Universidade Federal da Paraíba - UFPB - João Pessoa - Paraíba - Brasil.

2 Universidade Federal do Rio Grande do Sul - UFRGS - Porto Alegre - Rio Grande do Sul - Brasil.
} 


\section{INTRODUÇÃO}

A Educação Popular no Brasil se difunde nos anos 1960, em um contexto de efervescência política, tendo como lócus os movimentos sociais. Característica que se estendeu para as décadas seguintes, influenciando práticas educativas que têm como sujeitos as classes populares. Ação educativa que se realiza tanto no espaço escolar como não escolar, caracterizando-se "como o trabalho social agenciado através do qual são criadas situações e processos instrumentais de transferência de saber" (BRANDÃO, 1995, p. 11). Trata-se, portanto, de ações sociais educativas desenvolvidas por instituições oficiais ou da sociedade civil, as quais Brandão (1995) denomina de agências sociais, que prestam um serviço junto a um determinado grupo social.

As ações educativas que emergiram no início dos anos de 1960 aconteceram, principalmente, nas regiões Norte e Nordeste, contribuindo para a formação de um pensamento pedagógico emancipatório, o qual passa a ser referência para as práticas educativas no Brasil, na América Latina e no Caribe. Influência que pode ser observada no final da década de 1970 e no início dos anos de 1980, no movimento de Educação Popular no Brasil.

O Serviço de Educação Popular (SEDUP) surge nesse contexto, em 1981, por iniciativa da Igreja Católica alinhada à Teologia da Libertação. Sua presença na Paraíba, com ações educativas em diferentes contextos, teve papel significativo no movimento de Educação Popular, seja no período autoritário militar, com ações educativas voltadas para o processo de retomada dos movimentos populares, seja no momento de reconstrução da democracia, denominado de "transição democrática".

O presente artigo apresenta como problemática a contribuição do SEDUP, a partir de sua história e de sua memória nesses dois contextos: resistência ao autoritarismo político e período de transição democrática no Brasil. Tem como recorte histórico as décadas de 1980 e de 1990.

A investigação tem um caráter qualitativo, sendo realizada por meio da análise de documentos, caracterizando-se como uma pesquisa documental, com acesso a mais de 100 documentos. Nesse percurso metodológico, o conceito de memória nos ajudou a pensar sobre o conjunto de práticas educativas documentadas, constituindo-se como referencial importante para o processo de sistematização da memória e da história do SEDUP, a partir das contribuições dos estudos de Halbawachs (2006) e de Le Goff (1990).

O estudo é resultado do pós-doutorado na Universidade Federal do Rio Grande do Sul (UFRGS), em 2019, o qual buscou refletir sobre a Educação Popular no Nordeste brasileiro, a partir da experiência educativa do SEDUP na região do Brejo da Paraíba. A análise buscou refletir sobre a trajetória histórica e a memória dessa instituição e suas ações educativas como parte do movimento de Educação Popular na região.

O artigo está organizado em cinco partes. Na primeira, apresentamos a problemática de pesquisa, destacando a experiência educativa e a sua importância em um período de resistência política e de transição democrática, e a metodologia de pesquisa. Na segunda parte, situamos o debate sobre a Educação Popular numa perspectiva histórica, com uma reflexão acerca desse pensamento pedagógico, as mudanças e as continuidades relativas à refundamentação da Educação Popular. A terceira traz a análise dos conflitos sociais no período de criação do SEDUP e 
suas ações educativas como propulsoras do movimento de Educação Popular. Na quarta, apresentamos as ações educativas no período de transição democrática. Por fim, nas considerações finais, apontamos os desafios da ação educativa e os indicativos que poderão iluminar as práticas educativas populares na atualidade.

\section{O DEBATE SOBRE EDUCAÇÃO POPULAR}

Julgamos importante demarcar, neste estudo, a compreensão sobre as práticas educativas que estamos denominando de Educação Popular. Compartilhamos do pensamento de Brandão (2002) de que tais práticas não têm origem nos anos de 1960. Em fins do século XIX e começo do $X X$ já se tinha notícia de projetos de educação em pequenas escolas de bairros operários de São Paulo que recebiam operários e seus filhos, com uma perspectiva crítica ao modelo de educação vigente. Como afirma Brandão (2002, p. 140): “[...] este poderá ter sido um primeiro momento em que uma experiência pedagógica com perfil alternativo e transgressivo de uma educação popular foi realizado entre nós".

Um segundo período ocorreu nos anos de 1920, com a luta por escolas públicas para as classes populares, com um caráter gratuito e laico. Estudos realizados por Beisiegel (1974) e Brandão (2006) trataram de analisar as experiências desse período, as quais foram significativas para o acesso à educação das classes populares.

O terceiro momento ocorreu nos anos de 1960, fase de disseminação da Educação Popular, quando emergem os movimentos de Cultura Popular, tempo de efervescência política que marcou história da Educação Popular no Brasil. Movimento teórico e prático que resultou na formação de uma corrente do pensamento pedagógico, com repercussão em vários países do mundo, com destaque para a América Latina e o Caribe.

Nesse período, no Brasil, emergem experiências educativas populares que vão se constituir em referências: o Movimento de Educação de Base (MEB), o Movimento de Cultura Popular (MCP), - Centro Popular de Cultura (CPC) e a Campanha de pé no chão também se aprende a ler. Movimentos que, no primeiro momento, privilegiou a cultura popular e a alfabetização de adultos como uma das suas principais ações. Em seguida, expandiu-se para outros campos de atuação, sempre atento à valorização da cultura popular e à emancipação dos sujeitos expostos à dominação cultural, econômica e política. O educador Paulo Freire foi uma referência para a reflexão teórica e a prática pedagógica dessas experiências, o que se constituiu em um "paradigma epistemológico assumido como matriz de interpretação a partir da qual os coletivos sociais leem e se relacionam com a realidade e na qual as subjetividades são primordiais" (CARRILLO, 2013, p. 15).

Na Paraíba, a Campanha de Educação Popular (CEPLAR) teve papel relevante, desenvolvendo ações de alfabetização de adultos, tendo como principal território para suas ações as áreas rurais, chegando a ser referência no movimento de Educação Popular no Nordeste (FÁVERO; SOARES JUNIOR, 1992).

A interrupção desse movimento pelo regime militar em 1964 não conseguiu destruir esse pensamento pedagógico. Ao contrário, passou a orientar as ações educativas realizadas nas áreas 
rurais e nas periferias urbanas, mesmo sob as atrocidades de um regime autoritário. De forma subterrânea, adentrou pelos mais longínquos territórios, contribuindo para a resistência democrática e o fortalecimento da organização popular, influenciando o momento seguinte.

O quarto período, localizado nas décadas de 1970 e de 1980, chega até aos anos de 1990 (BRANDÃO, 2002, p. 159). Nesse tempo, a Educação Popular, preservando a sua tradição histórica, emerge junto aos movimentos sociais, constituindo uma ação de resistência e de luta pela democratização da sociedade e pelo direito à educação pública, período marcado pelo fim da ditadura militar e pela transição democrática (DOIMO, 1995).

As mudanças políticas ocorridas nos anos de 1990 acarretaram alterações na vida social, incidindo sobre a Educação Popular, exigindo novos instrumentos teóricos e metodológicos para a interpretação da realidade e para a prática educativa. Movimento que é resultado de uma ação global com impacto na sociedade e no Estado, denominado de neoliberalismo. Movimento acompanhado pelo que se denominou de "crise de paradigma", ou seja, uma "crise filosóficacientífica da modernidade" (ZITKOSKI, 1999, p. 83). Orientação que se expandiu no mundo com consequências para o pensamento crítico, colocando desafios para a Educação Popular, sem perder a sua perspectiva de emancipação social, e influenciando o movimento definido como de refundamentação e de vigência da Educação Popular.

Esse debate teve início no final dos anos de 1980, com o objetivo de repensar os fundamentos teóricos e práticos da Educação Popular, à luz das mudanças em curso nas várias esferas da vida social, tendo como um dos espaços de debate o Conselho de Educação Popular da América Latina e Caribe (CEAAL), orientado pela seguinte questão: qual o papel, a vigência e a contribuição da Educação Popular para os cenários em mudanças no mundo, sobretudo na América Latina e no Caribe?

Um primeiro aspecto, nesse debate, é o entendimento da Educação Popular como um "paradigma" epistemológico, o qual se caracteriza por uma matriz interpretativa que ajuda a compreender a realidade, associado tanto à reflexão teórica quanto à prática social. (CARRILLO, 2013, p. 16).

Um segundo elemento é o posicionamento de que a Educação Popular tem um acúmulo histórico, desde o pensamento de educadores latino-americanos, a exemplo de Simóm Rodrigues e José Martí, com contribuições importantes para o pensamento pedagógico latino-americano (STRECK, 2010). Somados a esses, outros educadores, como Paulo Freire, com uma obra que fundamenta esse pensamento pedagógico emancipador.

Um terceiro ponto diz respeito à dimensão emancipadora. Mesmo que a referência seja o campo político-pedagógico da Educação Popular, não devemos restringir essa dimensão a esse campo. Essa perspectiva não é seu patrimônio, encontra-se dentro de um espaço mais amplo das teorias críticas e em outros campos de saberes. O acúmulo próprio desse pensamento pedagógico não pode menosprezar outras referências e autores que também têm uma posição crítica, devendo abrir um diálogo com esses pensadores.

Um quarto aspecto reconhece nas práticas educativas um potencial para a produção de saberes, pois, além do cabedal teórico como corrente pedagógica, a Educação Popular tem um acúmulo de saberes que serve de referência às práticas educativas que dinamizam as organizações 
e as redes. Por isso, deve-se reconhecer a diversidade de práticas e de atores que vêm gerando saberes em diferentes territórios em um movimento pedagógico popular (CARRILLO, 2013, p. 16).

Portanto, a Educação Popular é um movimento formado por uma diversidade de atores em diferentes territórios, que traz em suas práticas uma sensibilidade para com a realidade dos sujeitos. Como afirma Carrillo (2013, p. 19), “[...] a educação popular incorpora como prática permanente a realização de leituras críticas dos contextos locais, nacionais e continentais em que se desenvolve".

No Brasil, quando olhamos para o período de visibilidade dos movimentos de Educação Popular, esse posicionamento já estava presente nos primeiros escritos de Paulo Freire, quando ele escreve sobre a Educação e a Atualidade Brasileira e a Pedagogia do Oprimido. A leitura do mundo pelos sujeitos é fundamental para a compreensão do seu lugar no mundo e da sua capacidade de transformar a realidade em que estão inseridos. Freire (2005) fala de uma pedagogia libertadora, chamando a atenção para a necessidade do desvelamento do mundo pelos oprimidos.

\begin{abstract}
A pedagogia do oprimido, como pedagogia humanista e libertadora, terá dois momentos distintos. O primeiro, em que os oprimidos vão desvelando o mundo da opressão e vão comprometendo-se, na práxis, com a sua transformação; o segundo, em que, transformada a realidade opressora, esta pedagogia deixa de ser do oprimido e passa a se a pedagogia dos homens em processo permanente de libertação (FREIRE, 2005, p. 46).
\end{abstract}

Ação e reflexão são fundamentais no pensamento de Freire para a realização da práxis. "É neste sentido que a práxis constitui a razão nova da consciência oprimida e que a revolução, que inaugura o movimento histórico desta razão, não pode encontrar viabilidade fora dos níveis da consciência oprimida" (FREIRE, 2005, p. 59). O autor renova essa perspectiva na Pedagogia da Esperança e, nesse reencontro com a Pedagogia do Oprimido, reafirma o seu pensamento pedagógico emancipatório (FREIRE, 2014).

Portanto, considerar os contextos para a compreensão das ações educativas é fundamental, visto que os territórios estão prenhes de saberes que devem ser considerados como ponto de partida para a leitura do mundo. Pensar a Educação Popular com essa perspectiva implica considerar os atores envolvidos nas diversas práticas, reafirmando o papel da Educação Popular em continuar tendo como referência as classes populares (DIEGO; CLAVIJO, 2009, p. 59).

Nessa perspectiva, a Educação Popular assume o compromisso com a continuidade do pensamento crítico e com a construção da autonomia dos sujeitos frente a um movimento neoliberal que quer impor um pensamento único.

\begin{abstract}
Faz-se notar que, em decorrência dessa realidade social acima mencionada, há inúmeras consequências para a organização e atuação prática dos Movimentos Sociais e da Educação Popular. É necessário repensar seus fundamentos teórico-práticos à luz desse contexto e das mudanças sociais em curso provocadas pela nova lógica da economia mundial. Mas, acima de tudo, impõe-se à Educação Popular reconstruir seus paradigmas de sustentação, pois estamos em um momento de progressiva complexificação da vida em sociedade a partir da qual os paradigmas tradicionais já não respondem aos novos desafios que surgem a cada dia. (ZITKOSKI, 1999, p. 73).
\end{abstract}

Nesse repensar dos fundamentos da Educação Popular, amplia-se o horizonte para compreender as realidades social e cultural. O pensamento marxista, com sua marca estrutural, já 
não era suficiente para entender aspectos da vida social não determinados exclusivamente pelas condições econômicas, visto que emergem na sociedade contemporânea novas demandas, tendo a cultura como elemento central, apresentando uma diversidade de sujeitos e de problemas que passam a fazer parte da vida cotidiana. Mesmo assumindo a crítica ao paradigma vigente que orientava a sua teoria e a prática educativa, referenciado pelo pensamento marxista, a Educação Popular não se afastou de sua perspectiva de emancipação social, continuou sua crítica à sociedade capitalista. O reconhecimento dos limites de uma visão estrutural determinista, com pouca abertura para a esfera da cultura e da subjetividade, o fez lançar mão de outros referenciais teóricos que ajudassem a compreender a realidade social e apontassem para mudanças em suas práticas educativas.

\section{O CENÁRIO POLÍTICO E ECLESIAL NA PARAÍBA NA DÉCADA DE 1980}

Os conflitos sociais na Paraíba já foram analisados por estudiosos das questões rurais, com estudos sobre as lutas sociais nos anos de 1950 e de 1960, quando as Ligas Camponesas protagonizaram a luta pela reforma agrária. Na região do Brejo, as mobilizações emergem nesse período e continuam em outros momentos históricos, com a participação de organizações de trabalhadores rurais.

A partir do final da década de 1970, assistimos à retomada das lutas pela terra, por melhores condições de trabalho e de salários. Com o avanço do capitalismo no campo e a entrada dos projetos estatais, a exemplo do Proálcool e do Projeto Nordeste, os quais impulsionaram a modernização conservadora, evidenciam-se situações de injustiça contra os trabalhadores rurais em relação à posse e ao uso da terra, evidenciando o desrespeito aos direitos trabalhistas.

Dois tipos de conflitos ganharam visibilidade: os conflitos de terra e os trabalhistas. Realidade que fez da região palco de lutas sociais e de retomada da mobilização sindical rural, com a participação da Igreja Católica como mediadora (TOSI, 1988; BERTOLAZZI, 1989); lutas marcadas pela violência por parte dos proprietários rurais e do Estado. Nesse período, existiam 135 áreas de conflitos localizadas em diferentes regiões, com destaque para a região do Brejo, com 28 áreas de conflitos em 11 municípios, segundo documento entregue ao INCRA em 1986, por ocasião do primeiro acampamento em sua sede (TOSI, 1988, p. 45). Os conflitos trabalhistas se deram em função do desrespeito aos direitos trabalhistas por parte dos senhores de engenhos e usineiros, problemática que se desenvolveu no território denominado de área canavieira e que resultou em mobilizações e greves nos anos de 1980, em função do processo de exploração e da precarização das condições de vida e de trabalho; com controle rígido no processo de trabalho e descumprimento dos direitos, além da ação de expropriação que levou muitos canavieiros a morarem nas pontas de ruas, como revela pesquisa realizada pelo SEDUP (SEDUP, 1986).

Essa situação fez emergir um processo de organização, mesmo frente a uma realidade de sindicatos frágeis, em sua maioria, controlados pelos proprietários de terra que exerciam o controle direto sobre os trabalhadores, ao mesmo tempo que provocou a renovação sindical, resultado da oposição nos sindicatos que tinham uma atuação de não defesa dos trabalhadores e de reforço aos sindicatos que assumiam a luta pelos direitos. 
A participação das organizações de apoio se destaca nesse processo, contribuindo para dar visibilidade aos conflitos sociais. Ressalta-se, aqui, o papel do SEDUP no âmbito educativo, com sua expertise no campo da Educação Popular, tendo como tarefa a assessoria política junto aos dirigentes sindicais e a produção de material pedagógico e informativo para a educação de base, utilizados nos períodos de campanhas trabalhistas, campanhas salariais, eleições sindicais e concentrações públicas junto às lideranças, animadores de comunidades, agentes de pastorais etc.

\section{O SERVIÇO DE EDUCAÇÃO POPULAR EM TEMPOS DE RESISTÊNCIA}

A criação do SEDUP ocorreu em um cenário político de resistência ao regime militar, em meio à aproximação da Igreja católica com a Teologia de Libertação, após a nomeação de D. Marcelo P. Carvalheira como primeiro bispo da Diocese de Guarabira, criada em 1980.

Iniciativa que surge pela necessidade de estender o apoio aos movimentos populares, por perceber o povo como "novo sujeito histórico". A partir desse entendimento, foi se concretizando na Igreja do Brejo a ideia de criar um serviço de educação que não fosse igual à escola e que contribuísse com a organização popular, tendo como orientação metodológica a Educação Popular, como afirma D. Marcelo em carta sobre a criação do SEDUP,

Daí ter pensado naquele primeiro esboço de projeto, tanto de formação histórica, política, jurídica, social, como também a formação de ministros, animadores de comunidades, de fé e culto. Tudo isso dentro da legítima Educação Popular, quer nos métodos, quer nas metas (SEDUP, 1981a, grifo nosso).

Proposta que trazia em seu formato a construção de um espaço que respondesse as demandas dos movimentos populares, orientado pela seguinte questão: "o que fazer para aumentar a consciência da classe trabalhadora?" A fala de um agente de pastoral da diocese, destacada por Silva (1992), revela essa preocupação.

Por que não fundarmos aqui no Brejo uma universidade popular? Um centro de estudo que possa oferecer cursos às lideranças do movimento popular, que reconte a história de nosso povo, onde o povo seja 'sujeito', que ensine não somente a ler, mas a pensar a nossa realidade por uma ótica crítica, sob o ponto de vista da classe trabalhadora, que contribua no processo de organização popular (SILVA, 1992, p. 46-47).

O debate acerca da criação de um serviço com as características acima descritas vai se desenhando como uma proposta de um centro com inspiração no pensamento pedagógico da Educação Popular, uma iniciativa em sintonia com o que estava ocorrendo em vários recantos do Brasil, com a criação de centros de educação popular (DOIMO, 1995).

As primeiras ações do SEDUP tiveram início em 1981, com uma estrutura mínima: abertura de um escritório com equipamentos e a formação de uma equipe, composta por uma pedagoga, uma secretária e colaboradores esporádicos, ligados à Universidade Federal da Paraíba (SEDUP, 1981b; SILVA, 1992, p. 52). Equipe que teve a tarefa de realizar as primeiras atividades junto aos grupos populares e sindicatos, além de mobilizar e de articular intelectuais para sua ampliação, como enfatiza Valéria Rezende: 
O SEDUP nasce no início da década de 80 dentro de uma rede internacional. Montei uma equipe de profissionais que tinham experiência da educação de base em vários países. Os meninos do PEM que foram para as universidades vinham à Guarabira, nos finais de semana, para engrossar a equipe do SEDUP. E a meta era que assim que se formassem se dedicariam a trabalhar no SEDUP (REZENDE, 2015).

A equipe recebeu intelectuais de movimentos católicos internacionais e brasileiros, além de estudantes universitários da região. Assim, foi se constituindo a equipe de educadores/as, com a participação de profissionais de diferentes áreas do conhecimento: pedagoga, sociólogo, jornalista, filósofo, economista e assistente social.

Nos primeiros anos, as ações se realizaram junto às CEBs, grupos populares e sindicatos, tendo como tarefa contribuir com a retomada da organização popular interrompida pelo golpe militar. Período com apoio direto às organizações e sujeitos para fomentar a organização de base.

$\mathrm{Na}$ área rural o trabalho acontecia em estreita relação com a pastoral rural da Igreja Católica, com ações relacionadas à produção comunitária, à educação sindical e à alfabetização. Um segundo campo de atuação era a periferia urbana, nas associações e grupos de moradores de bairros. As principais atividades eram a realização de cursos sobre direitos trabalhistas, previdência, elaboração de boletins informativos e pesquisa sobre as condições de vida dos moradores.

Na medida em que as atividades foram se consolidando, os objetivos do SEDUP foram sendo sistematizados, chegando aos seguintes:

Proporcionar junto aos grupos da população pobre maior acesso às informações que necessita para revitalizar os conhecimentos e as expressões da própria cultura popular;

Ajudar os grupos populares a criar e apropriar-se de uma metodologia pedagógica adequada às suas necessidades de autoeducação, que possa ser usada permanentemente;

Formar educadores e comunicadores populares no seio das próprias comunidades e grupos populares, que aumente sua autonomia;

Capacitar as lideranças populares para suas tarefas organizativas;

Fazer com que se crie um sistema pelo qual os conhecimentos, expressões e técnicas criadas e possuídas pelas classes populares da região sejam organizadas, registradas e divulgadas entre os grupos e comunidades populares (SEDUP, 1982).

O volume de atividades exigiu a estruturação na organização interna, definição de linhas de ação e divisão de responsabilidades entre os educadores/as. Em 1984, o SEDUP se organizou por setores, constituindo núcleos de trabalho, definição que resultou na organização dos seguintes setores, como revela o quadro 01:

\section{Quadro 1 - SETORES DO SEDUP}

\begin{tabular}{|l|l|}
\hline \multicolumn{1}{|c|}{ Setores } & \multicolumn{1}{c|}{ Objetivo } \\
\hline Alfabetização & Alfabetizar lideranças para atuação nas organizações populares. \\
\hline Assessoria sindical & Apoiar sindicatos e oposição em sua organização. \\
\hline Comunicação Popular e & Produzir material pedagógico para as ações educativos. \\
\hline
\end{tabular}




\begin{tabular}{|l|l|}
\hline produção de material & \\
\hline Documentação & $\begin{array}{l}\text { Registrar as atividades e documentar as informações produzidas por } \\
\text { outras organizações e pela imprensa. }\end{array}$ \\
\hline Formação de base & $\begin{array}{l}\text { Capacitar trabalhadores para assumir os sindicatos e fortalecer a } \\
\text { organização popular. }\end{array}$ \\
\hline Mulheres & $\begin{array}{l}\text { Fortalecer a participação da mulher no sindicato; aumentar a } \\
\text { participação na luta por terra e salário. }\end{array}$ \\
\hline Pequenos produtores & $\begin{array}{l}\text { Criar um método de atuação que transforme o cotidiano em } \\
\text { experiência educativa; conhecer a situação dos pequenos agricultores } \\
\text { da região. }\end{array}$ \\
\hline Pesquisa & Conhecer a realidade da região. \\
\hline
\end{tabular}

Fonte: SEDUP.

\section{AS AÇÕES EDUCATIVAS POPULARES}

A alfabetização de adultos teve início em 1982, em continuidade à ação realizada pelo Projeto Educativo do Menor (PEM), iniciada em 1980. A alfabetização se realiza em decorrência da situação de analfabetismo na região e da necessidade das lideranças que emergiam dos grupos populares, para melhorar o desempenho nas atividades sindicais. A ação alfabetizadora tinha como referência o método de Paulo Freire. Em 1984, 20 os grupos de alfabetização estavam em funcionamento, em diferentes municípios da região do Brejo (SEDUP, 1984). Considerando a dimensão que ganhou essa ação, em 1984, foi criado o setor de alfabetização, como parte do processo de organização que estava em curso na instituição. As ações se realizavam nos seguintes aspectos: alfabetização direta nos grupos, capacitação de alfabetizadores e planejamento pedagógico.

As atividades de assessoria aos sindicatos rurais e aos grupos de oposição aconteceram desde o início do SEDUP. Tinham como objetivo renovar a organização sindical, tendo em vista que a maioria dos sindicatos rurais não desenvolvia uma ação em defesa dos direitos dos trabalhadores, em função de sua vinculação com o poder local (TOSI, 1988). A organização das semanas sindicais com ações educativas e campanhas trabalhistas, realizadas em 1981, 1982 e 1983, foram momentos de mobilização de base e de massa com concentrações públicas no $1^{\circ}$ de maio. Ação que se intensificou e exigiu a formação de um setor específico para desenvolver as atividades nesse campo de trabalho, a exemplo do acompanhamento das eleições sindicais com a participação de chapas de oposição, que resultou em um processo de renovação sindical.

A comunicação e a documentação fizeram parte das ações do SEDUP desde sua origem, com o objetivo de construir metodologias de comunicação popular, material pedagógico e capacitação de comunicadores populares para o uso das tecnologias populares. Atividade que começou com a produção de folhetos e cartilhas, elaborados de forma simples, com ilustrações e impressos em mimeógrafo, com o objetivo de auxiliar metodologicamente nas reuniões de base, em sua maioria com um público analfabeto. Com a introdução de outras tecnologias, a produção de 
conjuntos de audiovisuais e de filmes em super-8, realizada inicialmente, foi substituída pelo vídeo com o uso da tecnologia VHS.

A documentação popular foi uma atividade presente no SEDUP. Um acervo de publicações produzidas por movimentos sociais e centros de assessoria foi sendo construído ao longo dos anos, como forma de preservação da memória dos movimentos populares, com o objetivo de subsidiar a elaboração de materiais pedagógicos.

A ação de formação de base foi realizada desde o início e logo se expandiu, em razão das demandas apresentadas pelos sindicatos. Uma equipe foi formada para desenvolver essa atividade junto aos grupos de base, em particular na área rural. O objetivo era desenvolver ações educativas com vistas à formação política e sindical, além de suscitar o surgimento de novas lideranças sindicais na base. No início, o trabalho era realizado pelos educadores/as do SEDUP. Com a realização de um processo de capacitação de lideranças, passou a ser desenvolvido também por monitores populares, ampliando o seu alcance para outras localidades não atingidas pelos educadores do SEDUP, os quais passaram a priorizar a formação e o acompanhamento pedagógico.

A ação com as mulheres tem início a partir da organização das mulheres camponesas na pastoral rural no começo dos anos de 1980. Em função dessa iniciativa, surgiu a demanda para que o SEDUP colaborasse com esse processo organizativo, disponibilizando uma educadora para apoiar a organização das trabalhadoras rurais. Nesse tempo, o SEDUP desenvolveu ações de formação política, de mobilização e de produção de material pedagógico, trabalho que resultou na organização do Movimento de Mulheres Trabalhadoras do Brejo (MMT).

As atividades de tecnologia alternativa se realizavam junto aos pequenos produtores e tinham como objetivo contribuir para a melhoria da produção dos agricultores através da difusão e do uso de tecnologias alternativas ou apropriadas. As ações desenvolvidas tinham como perspectiva criar métodos no âmbito da produção agrícola, por meio da construção de unidades de experimentação com o uso de tecnologias de menor impacto no meio ambiente, as quais pudessem ser observadas e comparadas pelos agricultores em relação às formas "tradicionais" da produção. O conhecimento produzido através das unidades experimentais e a troca de saberes possibilitavam o desenvolvimento de ações educativas, fazendo com que houvesse um aprendizado para a utilização de novas formas de produzir com o uso de novas tecnologias.

Por fim, as ações de pesquisa voltadas para a investigação sobre a realidade na região do Brejo. Atividade que ganha solidez a partir de 1983, quando o SEDUP decide realizar uma pesquisa sobre as condições de vida e de trabalho na zona canavieira, ação que demandou um volume maior de trabalho, com contratação de consultoria, além de firmar uma parceria com professores da Universidade Federal da Paraíba, campus de Campina Grande.

\section{O SEDUP EM UM CONTEXTO DE TRANSIÇÃO DEMOCRÁTICA: MUDANÇAS E CONTINUIDADES}

A década de 1980 se caracterizou por um tempo de reconstrução da democracia, tendo como acontecimentos importantes o fim do regime militar, em 1985, a promulgação da Constituição, em 1988, e a eleição direta para presidente da República, em 1989. Fatos que 
influenciaram o período denominado de "transição democrática", resultado da mobilização da sociedade civil.

Com o pensamento neoliberal já em curso em outros países, começou a penetrar também no Brasil, tendo como marco a gestão do presidente Fernando Collor de Melo, iniciada em 1990, adotando medidas políticas e econômicas que impactaram a vida social. Modelo que teve continuidade em toda a década com o governo de Fernando Henrique Cardoso.

Nesse cenário, a Educação Popular vivenciou mudanças no campo epistemológico, objetivando a continuidade da sua tarefa de compreender a realidade e, ao mesmo tempo, desenvolver práticas educativas que fossem capazes de atender aos novos tempos na sociedade.

Desde o início do século, o conselho de Educação de Adultos da América Latina - CEAAL colocou no continente o debate em torno do papel da educação popular na construção de paradigmas emancipatórios. Tal preocupação parte do reconhecimento, em sua trajetória histórica, do caráter crítico, alternativo e transformador desta corrente pedagógica e da necessidade de revisar e atualizar seus fundamentos e perspectivas diante das mudanças recentes do contexto mundial e continental, em particular, da hegemonia total do neoliberalismo como pensamento único (CARRILLO, 2013, p. 15).

Debate que influenciou o SEDUP, com implicações em suas práticas educativas. $O$ ano de 1990 foi um marco para a redefinição de suas ações, tendo como referência essa discussão, acarretando mudanças e continuidades, de modo a acompanhar as novas configurações da realidade. Nesse contexto, iniciou um processo de repensar sua ação educativa, tendo em vista contribuir com a superação dos novos desafios colocados para os movimentos sociais populares no cenário político.

Esse momento coincide com o seu desligamento institucional da Diocese de Guarabira, transformando-se em uma associação sem fins lucrativos com personalidade jurídica, decisão que ocorreu em função das mudanças de rumo na Igreja Católica do Brejo, com o distanciamento da Teologia da Libertação e a saída de D. Marcelo P. Cavalheira da Diocese para assumir a Arquidiocese da Paraíba.

Diante de tais acontecimentos, em encontro de avaliação ocorrido em 1989, uma diversidade de questões foi levantada pelos educadores/as, as quais serviram de orientação para sua redefinição, com indagações relativas ao papel do SEDUP enquanto um serviço de Educação Popular; quais os sujeitos de suas ações; qual deveria ser o seu perfil institucional; como atender aos movimentos sociais na região do Brejo e, ao mesmo tempo, ficar em sintonia com o que estava acontecendo no mundo das ONGs na contemporaneidade (SEDUP, 1989).

As redefinições realizadas aconteceram em sintonia com as mudanças que estavam em curso nos contextos local e nacional. O SEDUP compreendeu os desafios para continuar com seu papel educativo junto aos movimentos populares, mesmo com alguns limites. A análise de Garcês (2006) nos ajuda a entender essas mudanças e o caminho trilhado pelo SEDUP.

Desse modo, a educação popular deve ser concebida como um componente das dinâmicas dos movimentos sociais, componente que colabora nos processos de autoconsciência individual e coletiva; reforça os processos de autonomia e criação cultural; favorece 0 desenvolvimento de iniciativas que formulam e recriam permanentemente "o público" e, no meio destes processos, favorece também "o salto da diversidade em direção aos processos inéditos e democráticos da unidade de nossos povos (GARCÊS, 2006, p. 89). 
A avaliação institucional indicou a necessidade de sua continuidade, mas, ao mesmo tempo, com o questionamento sobre qual o papel que deveria ter o SEDUP junto aos movimentos sociais, chegando-se a um consenso em relação à importância de sua permanência na região, em função de um vasto campo para uma ação educativa junto aos movimentos populares.

O SEDUP deve resgatar-se como entidade de educação popular, precisa rever sua linha de atuação dentro dos critérios da metodologia dialética; É necessário definir o papel da assessoria com clareza de objetivos; É necessário ver os setores progressistas da igreja que são aliados nossos; Pela complexidade de problemas do movimento, há necessidade de o SEDUP continuar (SEDUP, 1989).

Outro acontecimento importante nesse processo de redefinição foi o encontro com as organizações populares e sindicais, realizado em 1990, que resultou na indicação dos desejos dos movimentos sociais em relação à atuação do SEDUP: "organização e educação de base, acompanhamento pedagógico aos grupos e associações, formação sociopolítica para mulheres; articulação dos vários movimentos sociais na região, apoio às oposições sindicais no campo, formação política e sindical" (SEDUP, 1990).

Ao compreender esse movimento, o SEDUP passou a pensar suas práticas educativas, incluindo novas temáticas, novos sujeitos e territórios, sem perder a perspectiva emancipatória. Mesmo em um contexto adverso, com ataques aos movimentos sociais e à Educação Popular, em decorrência da ascensão do pensamento neoliberal, a dimensão política em favor dos sujeitos populares foi um compromisso que teve continuidade. As novas linhas de trabalho buscaram se adequar ao tempo político e ao contexto em que os movimentos populares estavam inseridos.

Portanto, as ações desenvolvidas no período de 1990 a 2000 visaram favorecer a ação dos atores sociais em um novo contexto de participação nos espaços públicos e incidência nas políticas públicas, o que se revelava no momento em âmbito nacional e local como um campo de atuação para a Educação Popular (PONTUAL, 2006).

\section{Quadro 2 - PROJETOS INSTITUCIONAIS}

\begin{tabular}{|l|l|}
\hline \multicolumn{1}{|c|}{ Ano } & \multicolumn{1}{c|}{ Temática } \\
\hline 1990 & Mobilização, organização popular e formação de base \\
\hline $1991-1993$ & Políticas públicas e formação política \\
\hline 1992 & Papel dos sindicatos no contexto contemporâneo \\
\hline $1994-1996$ & Políticas públicas, formação política e geração de renda \\
\hline $1997-1999$ & Capacitação e participação em conselhos gestores \\
\hline $1998-2000$ & Desenvolvimento local e orçamento público \\
\hline 1999 & Políticas públicas e cidadania \\
\hline
\end{tabular}

Fonte: SEDUP. 
Atento à realidade dos movimentos sociais e à sua tarefa enquanto uma instituição que trabalha com ações educativas, o SEDUP elege as temáticas da cidadania, da participação e das políticas públicas como referências para a realização de suas ações. Trata-se, portanto, de um movimento de redefinição, desencadeado pelas mudanças internas na instituição e no âmbito da sociedade, que vão redirecionando as formas de ação dos movimentos sociais, no sentido de um reposicionamento acerca do papel da sociedade civil no âmbito das políticas públicas a partir do início da década de 1990, aspectos que vão sendo evidenciados nas próprias temáticas dos projetos de ação. O que levou o SEDUP a perceber a contribuição e o papel da Educação Popular nos diferentes cenários políticos, sociais e culturais em que se encontrava a sociedade, orientando suas ações na perspectiva de um olhar sempre atento à realidade e ao contexto em que estavam inseridos os sujeitos populares, elemento fundamental do pensamento pedagógico da Educação Popular.

\section{CONSIDERAÇÕES FINAIS}

Considerando a trajetória histórica da Educação Popular, a experiência desenvolvida pelo SEDUP na região do Brejo paraibano pode ser pensada dentro de dois momentos históricos distintos. O primeiro, caracterizado por um contexto de resistência à ditadura militar, em um momento de distensão. O segundo, marcado por um cenário de construção da democracia, que se denominou de "transição democrática", assinalado por uma abertura política que possibilitou uma ampliação da ação sociopolítica dos sujeitos populares. Contextos entrelaçados por mudanças e por continuidades no processo de resistência, demarcado por ações educativas que tiveram como referência a Educação Popular e os movimentos sociais.

O SEDUP desenvolveu uma ação educativa popular, tendo como sujeitos os trabalhadores/as rurais, com toda a sua diversidade, e os moradores de bairros populares: mulheres, jovens e adultos, lavadeiras e empregadas domésticas. Ação que contribuiu para a retomada das organizações sindicais e populares, as quais se fortaleceram e ganharam autonomia com atuação na cena pública, denunciando e reivindicando melhores condições de vida e justiça social, sendo constituídas por sujeitos políticos coletivos.

Ação coletiva que articulou outros atores enquanto mediadores na construção de um movimento de Educação Popular na Paraíba, com destaque para a Igreja Católica, universidades e centros de assessoria. Experiência que revela a continuidade do movimento de Educação Popular da década de 1960 e expressa a vitalidade da Educação Popular em distintos territórios e junto aos sujeitos subalternos na contemporaneidade.

As mudanças na sociedade na década de 1990 exigiram do SEDUP uma redefinição de suas ações, no sentido de se aproximar de um novo contexto político, e assim dar continuidade à sua contribuição política e educativa, tendo em vista contribuir com a democratização da sociedade, ampliando suas ações a novos atores para a participação cidadã nos espaços públicos para a incidência política e controle social das políticas públicas.

Tendo como referência esse cenário político, o SEDUP incorporou em suas ações a formação política para as lideranças populares, voltada para a participação nos espaços públicos 
institucionais, sem abandonar a formação sindical junto aos trabalhadores rurais, com novas temáticas em suas atividades, novos sujeitos e novos territórios. Trata-se de uma reconfiguração com o objetivo de se aproximar da realidade política dos movimentos sociais e, assim, continuar a sua tarefa no campo da Educação Popular, contribuindo, ao mesmo tempo, para iluminar novas práticas educativas populares na contemporaneidade.

\section{REFERÊNCIAS}

1. BEISIEGEL, Celso Rui. Estado e educação popular no Brasil. São Paulo: Pioneira, 1974.

2. BERTOLLAZI, Analisa. Novo sindicalismo no campo paraibano: continuidades e mudanças. 1989. 269 f. Dissertação (Mestrado em Sociologia Rural) - Universidade Federal da Paraíba, Campina Grande.

3. BRANDÃO, Carlos Rodrigues. Educação Popular na escola cidadã. Petrópolis: Vozes, 2002.

4. BRANDÃO, Carlos Rodrigues. Em campo aberto. São Paulo: Cortez Editora, 1995.

5. CARRILLO, Alfonso Torres. Educação popular como prática política e pedagógica emancipatória. In: STRECK, Esteban. Educação popular: Iugar de construção social coletiva. Petrópolis: Vozes, 2013.

6. DIEGO, H. Duque; CLAVIJO, J. Pablo. Democracia participativa: aportes al debate sobre la democracia participativa y nuevas relaciones gobierno - sociedade. La Piragua, n. 28, Ciudad de Panamá, 2009.

7. DOIMO, Ana Maria. A vez e a voz do popular: movimentos sociais e participação política no Brasil pós 70. Rio de janeiro: Relume-Dumaré/ANPOCS, 1995.

8. FÁVERO Osmar; SOARES JÚNIOR Everaldo Ferreira. CEPLAR - Campanha de Educação Popular (Paraíba, 1962-1964). Educação e realidade, Porto Alegre, v. 17, n. 02, jul./dez., 1992.

ISSN 0100-3143. Disponivel em:
<https://seer.ufrgs.br/educacaoerealidade/issue/viewlssue/3055/321>. Acesso em: 14 set. 2020.

9. FREIRE, Paulo. Pedagogia do oprimido. Rio de Janeiro: Paz e Terra, 2005.

10. FREIRE, Paulo. Pedagogia da esperança. Rio de Janeiro: Paz e Terra, 2014. 
11. GARCÊS, Mário. Educação popular e movimentos sociais. In: PONTUAL, Pedro; IRELAND, Timothy (org.). Educação popular na América Latina: Diálogos e perspectivas. Brasília: UNESCO/CEAAL, 2006.

12. HALBAWACHS, Maurice. A memória coletiva. Tradução de Beatriz Sidou. São Paulo: Centauro, 2006.

13. LE GOFF, Jacques. História e memória. Trad.: Bernardo Leitão. 5. ed. Campinas, SP: UNICAMP, 1990. (Coleção Repertórios).

14. PONTUAL Pedro. Educação Popular e Democratização das Estruturas Políticas e Espaços Públicos. In: PONTUAL, Pedro; IRELAND, Timothy (org.). Educação Popular na América Latina: diálogos e perspectivas. Brasília: Ministério da Educação; UNESCO, 2006.

15. REZENDE, Valéria. Entrevista. SEDUP - Serviço de Educação Popular. 30 anos: revista comemorativa. Guarabira, 2015.

16. SEDUP - Serviço de Educação Popular. Carta de D. Marcelo Pinto Carvalheira. Guarabira, 1981a.

17. SEDUP - Serviço de Educação Popular. Projeto institucional de financiamento. Guarabira, $1981 b$

18. SEDUP - Serviço de Educação Popular. Projeto institucional de financiamento. Guarabira, 1982.

19. SEDUP - Serviço de Educação Popular. Relatório setor de alfabetização. Guarabira, 1984.

20. SEDUP - Serviço de Educação Popular. Relatório de pesquisa "Aspectos das condições de vida e de trabalho dos assalariados da cana de açúcar do Brejo paraibano". Guarabira, 1986. Mimeo.

21. SEDUP - Serviço de Educação Popular. Relatório de avaliação. Guarabira, 1989.

22. SEDUP - Serviço de Educação Popular. Relatório reunião com movimentos sociais do Brejo. Guarabira, 1990.

23. SILVA, J. Barbosa da. Assessoria e movimento popular: um estudo do Serviço de Educação popular (SEDUP). 1992, 234 f. Dissertação (Mestrado em Educação), Universidade Federal da Paraíba, João Pessoa. 
24. STRECK, Danilo R. (org.). Fontes da pedagogia latino-americana: uma antologia. São Paulo: Autêntica, 2010.

25. TOSI, Giuseppe. Terra e Salário para quem nela trabalha: um estudo sobre os conflitos sociais no brejo paraibano. 1988. 264 f. Dissertação (Mestrado em Sociologia) - Universidade Federal da Paraíba, Campina Grande.

26. ZITIKOSKI, Jaime J. Horizontes da refundamentação em educação popular: uma proposta com base na razão dialógica de Freire e na comunicação de Habermas. 1999. 433f. Tese (Doutorado em Educação), Universidade Federal do Rio Grande do Sul, Porto Alegre.

\section{Orlandil Lima Moreira}

Centro de Educação/Departamento de Metodologia da Educação.

\section{Jaime José Zitikoski}

Faculdade de Educação/Departamento de Estudos Básicos.

\section{Como citar este documento:}

MOREIRA, Orlandil Lima; ZITIKOSKI, Jaime José. EDUCAÇÃO POPULAR NA PARAÍBA: MEMÓRIA E HISTÓRIA DO SEDUP. Reflexão e Ação, Santa Cruz do Sul, v. 29, n. 2, p. 25-40, mai. 2021. ISSN 1982-9949. Acesso em: . doi: $10.17058 /$ rea.v29i2.15984. 